\title{
Discovertebral destruction in ankylosing spondylitis complicated by spinal cord compression
}

\author{
P JOBANPUTRA, ${ }^{1}$ B KIRKHAM ${ }^{1}$ O DUKE, ${ }^{1}$ A CROCKARD,${ }^{2}$
} AND G S PANAYI

From the 'Rheumatology Unit, United Medical and Dental Schools, Guy's Hospital, London; and the ${ }^{2}$ National Hospital for Nervous Diseases, Maida Vale, London

SUMMARY A 56 year old man with ankylosing spondylitis and discovertebral destruction 윽 presented with signs of spinal cord compression that was the result of the soft tissue reaction $\vec{T}$ occurring at the level of the discovertebral destruction. This case emphasises the importance of early recognition, use of appropriate imaging techniques (computed tomographic myelography or magnetic resonance), and operative intervention in the management of this rare complication $\vec{\bigotimes}_{\infty}$ of ankylosing spondylitis.

Key words: back pain, CT scan, histology, laminectomy, neurological diagnosis.

Spondylodiscitis or discovertebral destruction (DVD) is a recognised feature of longstanding ankylosing spondylitis (AS). Such lesions usually present with acute well localised back pain, which is exacerbated by exercise and involves most commonly the dorsal and lumbar spine. ${ }^{1}$ The diagnosis is confirmed by the characteristic radiographic appearance, though tomography or skeletal scintigraphy may be required to show early lesion. ${ }^{2}$ This complication of AS usually pursues a benign clinical course, and neurological complications resulting from discovertebral destruction have rarely been reported ${ }^{3}$ despite sometimes extensive radiological changes. We report a patient who presented with spinal cord compression consequent on discovertebral destruction caused by AS.

\section{Case report}

A 56 year old man with ankylosing spondylitis first had symptoms in 1950 . The diagnosis was made seven years later. He received radiotherapy to the hips and spine between 1959 and 1963. In 1969 he

Accepted for publication 10 October 1987.

Correspondence to Professor G S Panayi, Rheumatology Unit, United Medical and Dental Schools, Guy’s Hospital, London SE1 9RT, UK. developed right shoulder pain and paraesthesia of $\stackrel{\mathbb{Q}}{\circ}$ his right hand. Radiographs showed ankylosis of his cervical spine below $\mathrm{C} 4$ with marked subluxation of $\mathrm{C} 3$ on $\mathrm{C} 4$. His symptoms resolved after posterior cervical fusion.

In 1976 two episodes of iritis occurred. He subsequently developed active peripheral arthritis requiring inpatient treatment. In 1977 he developed severe persistent pain in the dorsal spine, worse on walking and standing. There was local tenderness from D8 to D10. Radiographs showed fusion of D5 and D6 with anterior DVD at D9-D10. A radionuclide bone scan showed increased uptake at several $\frac{D}{2}$ levels of the thoracic lumbar spine. Some relief was obtained from local steroid and anaesthetic injec- N tions and from a short course of systemic steroids, but intermittent exacerbations of pain occurred in $N$ ensuing years. A left total hip replacement was $\omega$ carried out in 1985. He presented in September 1986 ? with sudden onset of 'electric shock' sensations on the medial aspect of both legs followed shortly by $\Phi$ weakness of his left leg and a two week history of + poor control of micturition.

On examination he was apyrexial with an anky- $\frac{\overrightarrow{\mathrm{O}}}{\mathrm{D}}$ losed spine, a marked gibbus of the mid-thoracic $\stackrel{\bigcirc}{\square}$ spine, and large effusions in both knee joints. $\stackrel{\mathbb{Q}}{\Omega}$ Neurological examination showed a pyramidal $\frac{0}{2}$ weakness of the left leg with brisk lower limb 

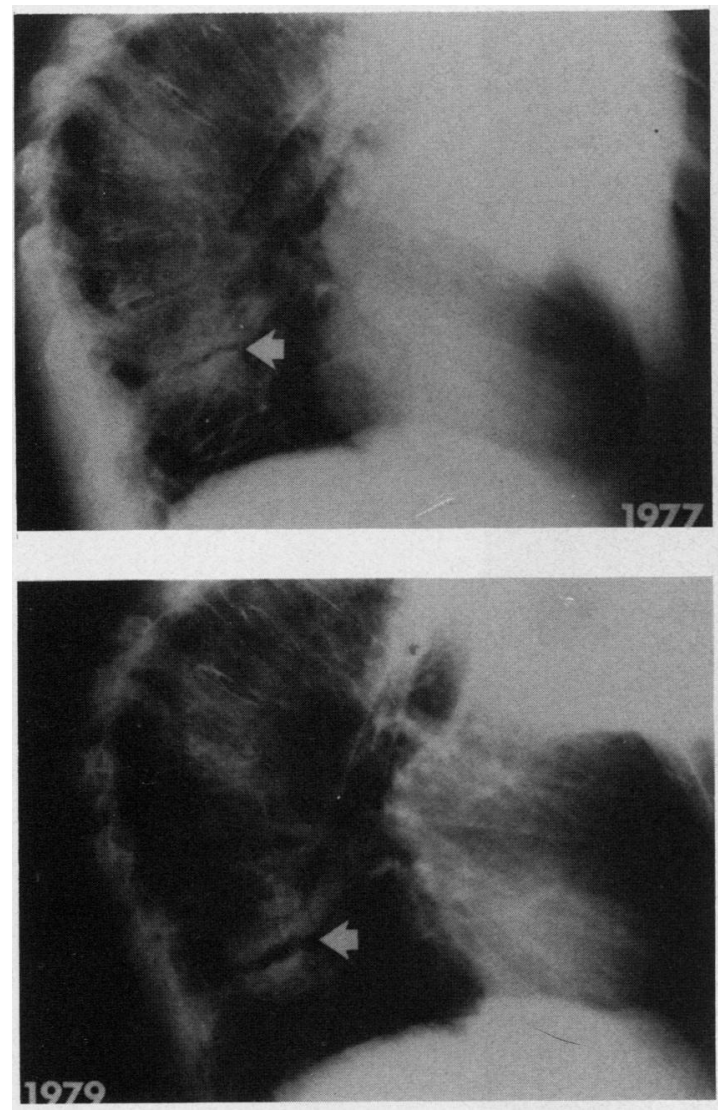

reflexes, absent lower superficial abdominal reflexes, and bilateral entensor plantar responses. A sensory level was present at the D9 dermatome on the left. Investigations showed haemoglobin $102 \mathrm{~g} / \mathrm{l}$, white blood cells $7.5 \times 10^{9} / 1$, erythrocyte sedimentation rate $110 \mathrm{~mm} / \mathrm{h}$. Rheumatoid factor test was negative. Radiographs showed that progression of the DVD lesion at the D9-10 disc space involved the entire inferior and superior surface of the disc (Fig. 1). No mobility of this segment was demonstrated on attempted flexion and extension radiographs of the dorsal spine. A plain computed tomographic (CT) scan showed no evidence of cord compression.

His symptoms and signs resolved completely with bed rest but reappeared at each attempt at mobilisation, subsiding again with bed rest. More persistent signs with weakness of the legs and altered perianal sensation led to CT myelography. This confirmed obstruction at the level of the DVD lesion (Fig. 2). At operation, sclerotic material which appeared to be calcified was seen at the site of the DVD lesion with granulation tissue encircling the dura and

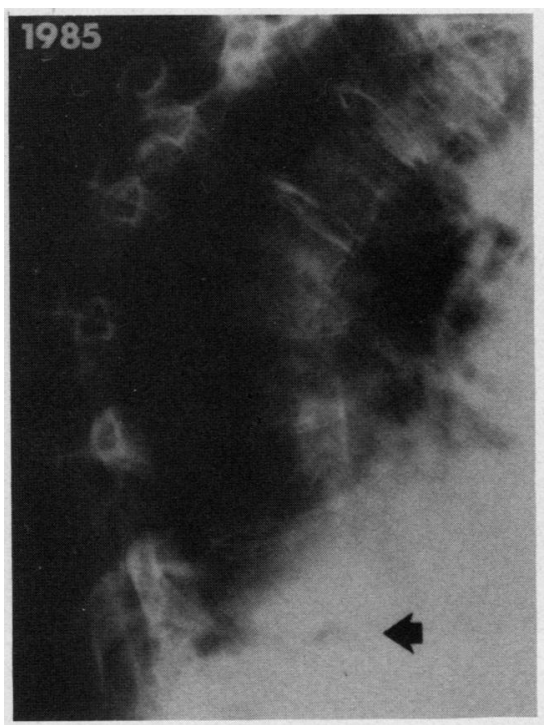

Fig. 1 Serial chest $x$ rays illustrating the progression of discovertebral destruction between 1977 and 1985.

preventing vascular pulsation around it. This tissue was removed posteriorly through a decompressive laminectomy at D9. A Hartshill loop fixation with sublaminar wires and cancellous bone chip grafting was used in the area to provide stability. Histology showed bone with trabeculae which were interspersed by fibrous and granulation tissue containing a mild chronic inflammatory cell infiltrate. Islands of new bone formation were also seen. After the operation progressive recovery of the power of the left leg occurred and mobility improved, the patient being able to walk with the aid of a stick. Control of micturition has returned to normal.

\section{Discussion}

Association of spinal cord compression with DVD in AS is a rare occurrence. Six previous examples of this complication have been published, with operative and histological findings similar to those reported here. ${ }^{4-9}$ Our case emphasises the role of the soft tissue reaction in causing spinal cord com- 


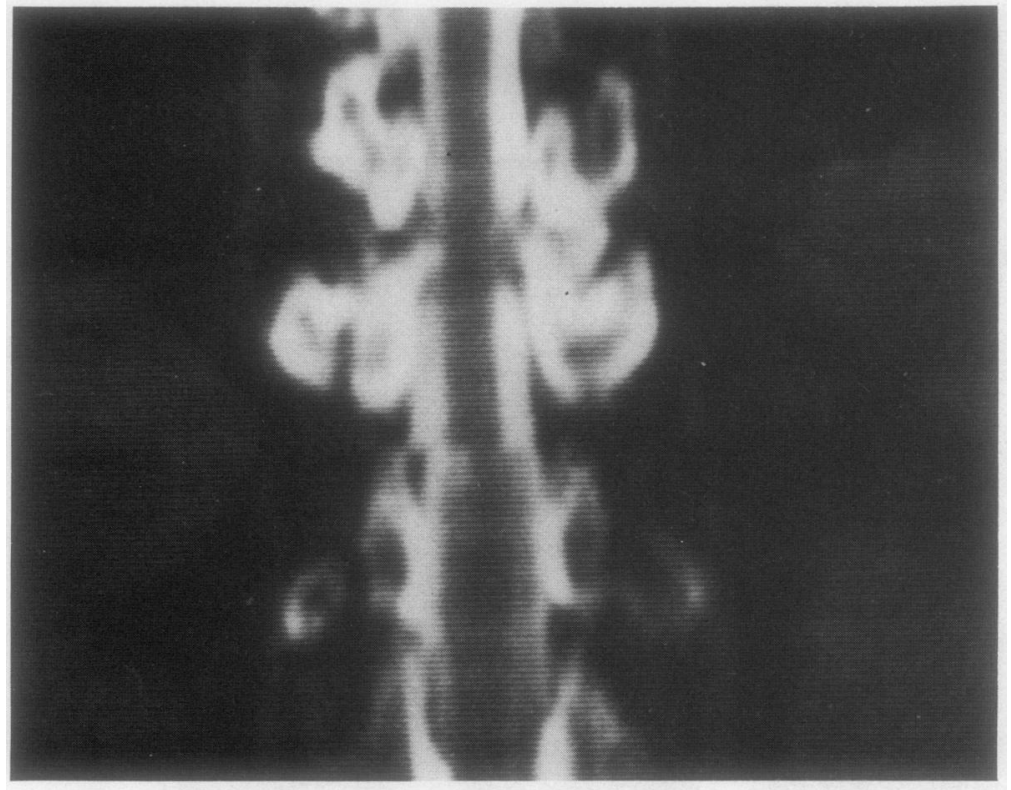

Fig. 2 CT myelogram

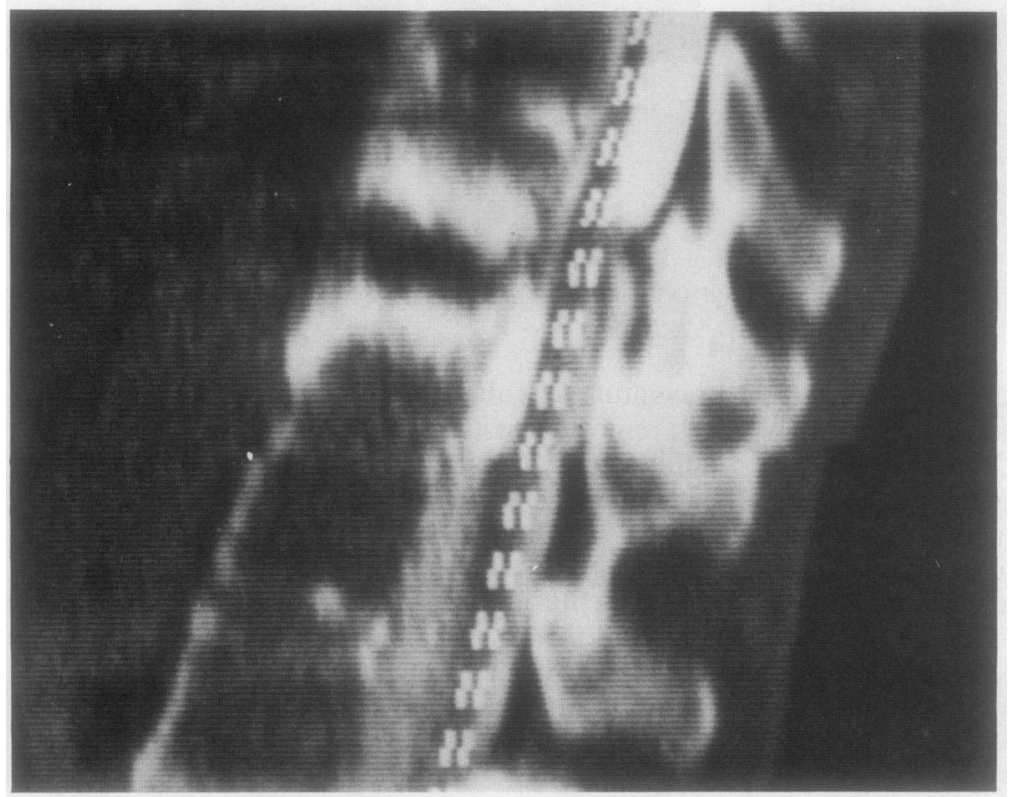
by soft tissue mass.

pression and is reminiscent of similar findings in the cervical cord complications of rheumatoid arthritis. ${ }^{10}$ The important clinical consequence of this is that CT scanning alone is an unsatisfactory method of defining the extent and severity of the lesion. Thus emphasis should be placed on either contrast studies such as CT myelography, despite the difficulties of carrying out such investigations in patients with advanced $\mathrm{AS}$, or magnetic resonance imaging. In particular, our case highlights the importance of the early recognition, investigation, and operative intervention in those cases where the spinal cord may be critically compromised, if a satisfactory outcome is to be achieved. This is in contrast with 
those cases of DVD associated with back pain alone, where conservative management appears to have an important role. ${ }^{2}$

Finally, it is generally considered that DVD lesions in AS arise as a result of a mobile segment. ${ }^{12}$ Nevertheless, our case leads us to suspect that uncontrolled disease activity may have an important additional role. This conclusion is suggested by continued disease activity and the absence of any clearly defined fracture in the posterior vertebral element at the level of the DVD. Further support for this notion is provided by the report of DVD and spinal cord compression occurring in a case of AS with a non-ankylosed spine. ${ }^{8}$

\section{References}

1 Cawley M I D. Chalmers T M. Kellgren J H. Ball J. Destructive lesions of vertebral bodies in ankylosing spondylitis. Ann Rheum Dis 1972; 31: 345-58.

2 Dunn N, Preston B, Lloyd Jones K. Unexplained acute backache in longstanding ankylosing spondylitis. $\mathrm{Br} \mathrm{Med} \mathrm{J}$ 1985: 291: 1632-4.
3 Wise C M, Irby W R. Spondylodiscitis in ankylosing spondylitis: variable presentations. J Rheumatol 1983; 10: 1004-6.

4 Lorber A. Pearson C M. Rene R M. Osteolytic vertebral lesions as a manifestation of rheumatoid arthritis and related disorders. Arthritis Rheum 1961: 4: 514-32.

5 Goldenburg G J. Logothetis J. Neurological manifestations in two cases of ankylosing spondylitis. $J$ Lancet 1961: 81: 448-50.

6 Castaigne P. Cambier J. Escourolle R, Masson M, Berger B. Étude anatomo-clinique d'un cas de spondylarthrite ankylosante compliquée d'un syndrome de compression de la moelle dorsale. Bulletins et Memoires de la Societe Medicale des Hopitaux de Paris 1965; 116: 321-7.

7 Kanefield D G, Mullins B P. Frechafer A A, Furey J G, Horenstein S. Chamberlain W B. Destructive lesions of the spine in rheumatoid ankylosing spondylitis. J Bone Joint Surg [Am/ 1969; 51A: 1369-75.

8 Good A E. Keller T S. Weatherbee L. Braunstein E M. Spinal cord block with a destructive lesion of the dorsal spine in ankylosing spondylitis. Arthritis Rheum 1982; 25: 218-22.

9 Jean-Baptiste G. Colleuil M. Compression médullaire dorsale d'origine inflammatoire au cours de la spondylarthrite ankylosante. Rev Rheum Mal Osteoartic 1985; 52: 635-7.

10 Crockard H A. Essigman W K. Stevens J M. Pozo J L. Ransford H O. Kendall B E. Surgical treatment of cervical cord compression in rheumatoid arthritis. Ann Rheum Dis 1985; 44: 809-16. 